\title{
A review on plant importance, biotechnological aspects, and cultivation challenges of jojoba plant
}

\author{
Jameel R. Al-Obaidi ${ }^{*}$, Mohammed Farouq Halabi ${ }^{2}$, Nasser S. AlKhalifah³, Shanavaskhan Asanar ${ }^{3}$, \\ Abdulrahman A. Al-Soqeer ${ }^{4}$ and M. F. Attia ${ }^{5}$
}

\begin{abstract}
Jojoba is considered a promising oil crop and is cultivated for diverse purposes in many countries. The jojoba seed produces unique high-quality oil with a wide range of applications such as medical and industrial-related products. The plant also has potential value in combatting desertification and land degradation in dry and semi-dry areas. Although the plant is known for its high-temperature and high-salinity tolerance growth ability, issues such as its male-biased ratio, relatively late flowering and seed production time hamper the cultivation of this plant. The development of efficient biotechnological platforms for better cultivation and an improved production cycle is a necessity for farmers cultivating the plant. In the last 20 years, many efforts have been made for in vitro cultivation of jojoba by applying different molecular biology techniques. However, there is a lot of work to be done in order to reach satisfactory results that help to overcome cultivation problems. This review presents a historical overview, the medical and industrial importance of the jojoba plant, agronomy aspects and nutrient requirements for the plant's cultivation, and the role of recent biotechnology and molecular biology findings in jojoba research.
\end{abstract}

Keywords: Simmondsia chinensis, Oil crop, Combat desertification, Desert plants

\section{Introduction}

Agricultural production from the desert or semi-arid lands is minimal due to prevailing harsh environmental conditions, thus most of the land is underused. Recent advances in biotechnology and modern agricultural farming have paved the way for expanding the scope of utilizing those arid lands for human endeavors. In such sense, Simmondsia chinensis (link) Schneider (commonly identified as jojoba but is also called deer nut, oat nut, wild hazel, and coffee berry) is a promising oil seed crop for the economic development of the arid and semiarid land all over the globe $[1,2]$. The jojoba plant is a monogenetic dioecious grey-green shrub belonging to Simmondsiaceae family. It is native to the North American deserts, especially those of south western states in the

\footnotetext{
*Correspondence: jr_alobaidi@yahoo.com; jameel@abi-nibm.my

${ }^{1}$ Agro-Biotechnology Institute Malaysia (ABI), c/o MARDI Headquarters, 43400 Serdang, Selangor, Malaysia

Full list of author information is available at the end of the article
}

United States (California, Arizona and Utah) and north western Mexico (Baja California and Sonora). Jojoba oil became widely known through the Spanish missionaries of the 18th and 19th centuries. Native Americans used the crushed seed oil for skin care and medicinal purposes. The Spanish missionaries became aware of its uses and introduced it to other parts of the world. The plant has been cultivated for more than 30 years in many countries worldwide, such as India, Mexico, Chile, Argentina, Australia, Tunisia, the Palestinian territories, Saudi Arabia and Egypt, due to its promising economic value [3], with the United States considered the largest jojoba oil-producing country, followed by Mexico. Jojoba seeds contain up to $65 \%$ of a light golden and odourless high-viscosity liquid-oil that differs from any other oil produced by plants (Fig. 1a, b) [4, 5]. It has wax-like unsaturated esters, consisting of a straight chain of fatty acids and higher alcohols $[4,6-8]$. The jojoba oil has been reported previously as having potential capabilities for the cosmetics and skincare industry [9]. This industry 

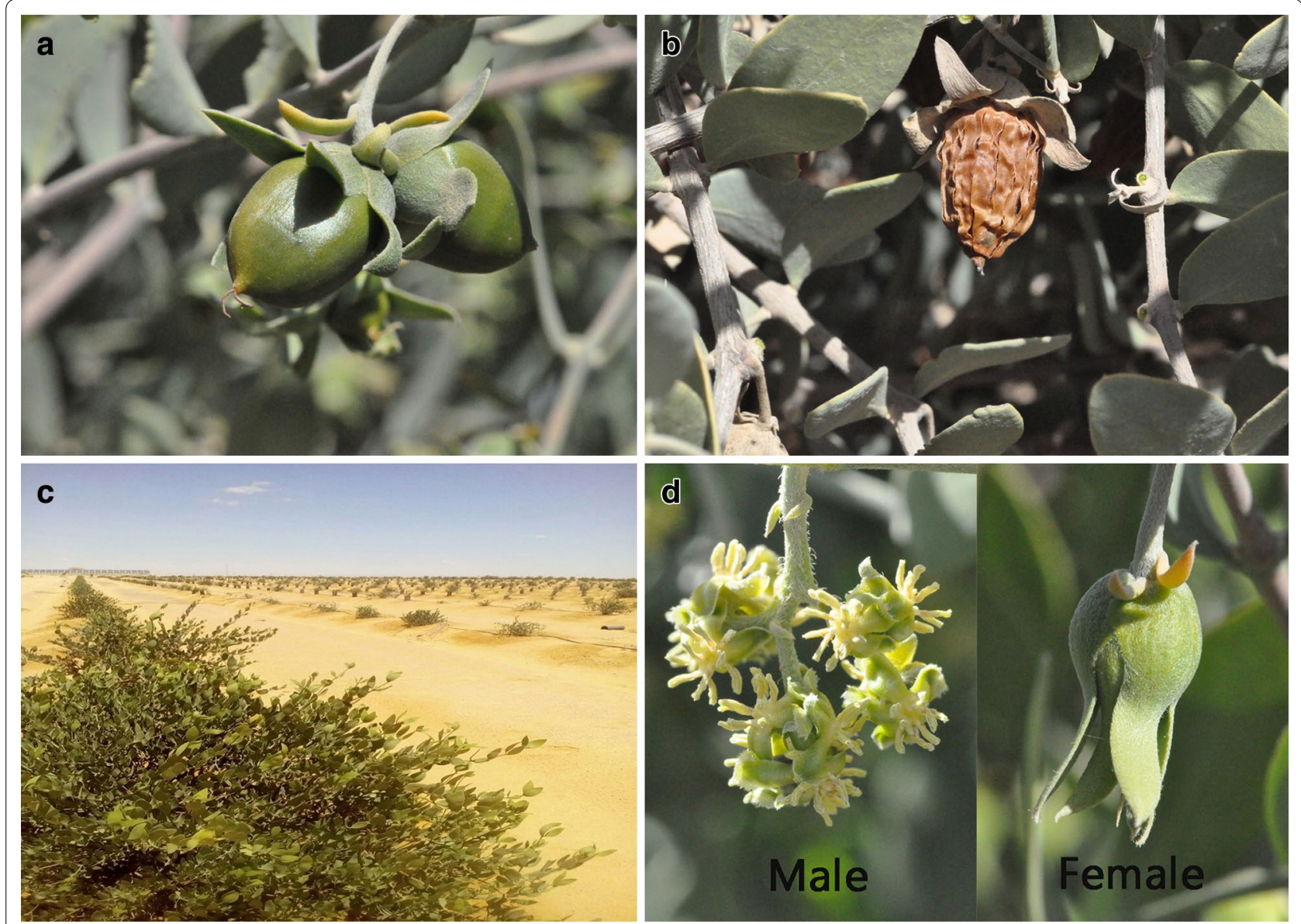

Fig. 1 a Jojoba green fruit and $\mathbf{b}$ jojoba ripened fruit, c jojoba cultivation to combat desertification in Qattara Depression, Egypt, $\mathbf{d}$ jojoba male and female flowers

seems to be the major marketplace for jojoba oil, with around two thousand tonnes being used annually, which is more than three-quarters of the total market portion [10]. As jojoba oil has a very similar texture to our oily secretion of the sebaceous glands, it is believed that consistent use can lead to the skin determining that it has produced enough oil, thus preventing excessive oil production. As jojoba oil is actually a wax formula, it also lasts significantly longer than other natural oils, making it a long-lasting addition to any skincare product. The jojoba seed oil also has pharmaceutical importance [11], synthetic polymer substitute [12], and is used in the bioenergy industry [13]. Interestingly, jojoba oil has some medicinal properties such as the relief of headaches and throat inflammation and in treating wounds [14]. Jojoba oil is reported to have anti-inflammatory activity, as well as antimicrobial [15] and antifungal/insecticidal properties [16]. Additionally, the jojoba meal left over after the oil-extraction process can also be used as a cheaper livestock feed ingredient [17]. Jojoba meal is reported to have the ability to replace up to $25 \%$ of the fish meal of Oreochromis niloticus (Nilotica fish) diets without any effects on its growth [18], and recently has been revealed to have potential anti-rodent activity [19]. Besides the seeds importance in this plant, the leaves have also recently been shown to have an important antioxidant flavonoid compound involved in treating disorders such as asthma, inflammation, and cancer [3]. It has been reported that male and female leaves together with seed coats have antibacterial and cytotoxic activity against cancer cell lines [20]. The jojoba plant is acclimatized to warm, dry environments and is now commercially cultivated in regions with a severe lack of available water for its seeds, and in areas where traditional farming practices were previously not commercially viable. This desert shrub is considered drought tolerant, requires very low levels of irrigation and soil fertility and can tolerate elevated temperatures (up to $55{ }^{\circ} \mathrm{C}$ ) [21, 22]. The jojoba plant shows some morphological alterations to survive in arid and semi-arid conditions-i.e., widespread rooting structure 
and comparatively thick and vertical orientation of jojoba leaves grown vertically and covered by a wax layer, falling off under water-deficiency conditions. The jojoba plant is a promising alternative to the threatened sperm whale oil [23], and it has the ability to control desertification around the world (Fig. 1c) [24]. Hence, this review aims to provide an overview of the plant, highlighting its importance in both industrial and medicinal applications, discussing the biotechnological aspects used in jojoba cultivation, including breeding, disease occurrence, and molecular biology, and suggesting future perspectives for the agronomical aspects, nutrient requirements, and overcoming cultivation issues.

\section{Medicinal and commercial importance of jojoba (Simmondsia chinensis)}

It has been reported that Native Americans have been using jojoba as an alternative therapeutic agent for colds, warts, sore throat, and wounds [25]. Many previous studies reported the antifeedant, insecticidal, and antifungal activities of jojoba [14].

\section{Antioxidant properties}

Plant extracts in general and jojoba oil extracts in specific, exhibit a hydroxylated phenolic compound containing an aromatic arene ring. These kinds radicals originated from phenolic compounds are reported to be less reactive and possess lower electron reduction potential compared to oxygen radicals [26]. Owing to these properties, the phenolic compounds are considered to be excellent radical chemical substances. Thus, phenolic metabolites have the prospect of scavenging reactive oxygen intermediates without raising further oxidative reactions. Interestingly, the presence of such phenolic compounds in jojoba was documented earlier in the literature [27].

Lipoxygenase is an important enzyme that synthesizes leukotrienes, which were reported to play a major role in the elucidation of free-radical diseases. Abdel-Mageed et al. [3] have reported the isolation of antioxidants and lipoexgenase inhibitors in jojoba. The researchers isolated 10 flavonoids and four lignans. They reported that flavonoid aglycosides showed stronger antioxidant and lipoxygenase inhibitory effects than their glycoside counterparts. They demonstrated that the antioxidant and lipoxygenase the inhibiting activity of flavonoids is dramatically reduced by the presence of a sugar moiety in the compound. In a similar study, the essential oil extracted from jojoba displayed an inhibition percentage of $7.81 \%$ based on a DPPH radical scavenging assay [28]. Fumonisins are mycotoxins that interfere with ceramide synthase, leading to the inhibition of synthesis of biological molecules and incurring lipid peroxidation in rat hepatocytes [29]. Ethanolic extract from jojoba was found to inhibit oxidative stress induced by fumonisins [30]. In addition to the presence of phenolic compounds, phytosterols, toccopherols and fatty acids, Al-Qizwini et al. [20] associated the antioxidant property of jojoba with the presence of simmondsin and its products: simmondsin-3'-ferulate, 4,5-didemethylsimmondsin and 4-demethylsimmondsin- $2^{\prime}$-ferulate. Similarly, the antioxidant property of jojoba oil based on nitric oxide and DPPH scavenging assays has been illustrated [31].

\section{Antimicrobial, antiproliferative and antifungal activities}

Jojoba extracts were also shown to possess antimicrobial and antifungal activities against several pathogens [32]. Previously, the antimicrobial and antiproliferative activities of jojoba oil obtained from Sudan were reported [33]. However, researchers reported that jojoba oil failed to show any antibacterial activity against MRSA, Bacillus subtilis B29, Pseudomonas aeruginosa 60690 or Salmonella choleraesuis. In contrast to this study, jojoba extracts and latex showed effective antimicrobial activity against some bacterial and fungal species such as Bacillus cereus, Salmonella typhimurium, Clostridium perfringens, Escherichia coli, Aspergillus flavus and Candida albicans [32]. The antimicrobial activity of jojoba oil is not surprising as it has been illustrated to show a striking chemical similarity to sperm whale oil [23].

Previously, the antifungal properties of simmondsin and simmondsin $2^{\prime}$-frulate have been evaluated [34]. The study revealed that simmondsin showed higher inhibition than simmondsin 2 -ferulate against all of the test fungi. Simmondsin was found to inhibit Botrytis fabae the most and was less sensitive in inhibiting Fusarium oxysporum. On the other hand, simmondsin 2 '-ferulate has the highest inhibitory activity on Rhizocotonia solani and B. fabae, as compared to its activity on Pythium debarianum and F. oxysporum.

In a similar study, Menghani et al. [35] reported the antimicrobial and antifungal properties of jojoba seed extracts. Their findings assert that the crude extracts have good antimicrobial activity against selected test bacteria and fungi. The importance of COX-2 in terms of carcinogenesis is shown to include: (i) increased production of prostaglandins, (ii) inhibition of apoptosis, (iii) conversion of procarcinogens into carcinogens, (iv) promotion of angiogenesis, (v) increased tumor-cell invasiveness, and (vi) modulation of inflammation and immune function [36]. Therefore, any phytochemical extract that inhibits COX-2 is said to exhibit anticancer activity by inducing apoptosis and suppressing proliferation. In agreement with this assertion, a noncynogenic cyclooxygenase inhibitor was isolated from jojoba, and it was shown to possess anticarcinogenic activity [16]. 


\section{Commercial importance of jojoba}

Jojoba is usually cultivated for its oil. These monoesters have several industrial applications especially, in cosmetics and pharmaceutics. Jojoba oil was filed as an embodiment in an oil blend for skin treatment [37]. The extraction of phosphate ores by froth flotation is considered to be the most efficient process employed in separating apatite from calcium minerals. Unfortunately, similar surface properties between apatite and calcite generally lead to non-selective adsorption of reagents, posing a setback in selective separation of these minerals, thus demanding a new approach. Jojoba oil treatment was found to enhance the surface properties of calcite and apatite, thus improving their selective flotation [38]. In industrial manufacturing processes, lubricants are widely used. There is no doubt that the extreme usage of petroleum-based oils considerably contributes to environmental pollution. Thus, exploring alternative oils from natural resources is a possible solution. Along with this line, vegetable oils are thought to be potential candidates for eco-friendly biolubricants. Using vegetable oils as lubricants is reported to have numerous advantages over petroleum-based lubricants, such as their good contact lubrication [39], superb lubricity [40], biodegradability, excellent viscosity-temperature parameters [41], and high viscosity indices coupled with very low volatility [42]. Additionally, plant-based biolubricants are said to have a high flash point due to the presence of high molecular weight triglycerides [43]. Research literature has demonstrated the use of jojoba wax as a biolubricant [44-46]. In this regard, [46] demonstrated that these properties of $S$. chinesis oil could be improved by chemical and physical methods and also by additive viscosity of the depends upon selection jojoba oil by partial sulfurization. Jojoba wax is reported to have been employed as a biolubricant [44]. Jojoba oil is known to be catalytically converted into biodiesel $[47,48]$. A summary of different applications of the jojoba plant is listed in Table 1.

\section{Agronomy aspects and nutrient requirements and diseases of the jojoba plant}

Jojoba, living in the bright desert sun, is a true heliophyte and tolerates the extreme daily fluctuations of temperature which commonly range through $-1{ }^{\circ} \mathrm{C}$ during the morning to daily extremes of $46{ }^{\circ} \mathrm{C}$ (shade readings). Seedlings are sensitive to light frosts of -1 or $-2{ }^{\circ} \mathrm{C}$. Mature shrubs are known to tolerate temperatures as low as $-9{ }^{\circ} \mathrm{C}$ [49]. Flowers are reported to be destroyed by late frosts although they are hardy in the bud stage [50]. The relatively low winter temperatures synchronized with soil moisture build up appear natural for jojoba reproduction. Optimum growth occurs in the range of $27-36^{\circ} \mathrm{C}$. A daily range of -1 to $50^{\circ} \mathrm{C}$ has been recorded in the Mexican desert habitat, but temperatures above

Table 1 Summary of the medicinal and industrial applications of jojoba (Simmondsia chinensis)

\begin{tabular}{|c|c|c|}
\hline Plant parts or products & Applications & References \\
\hline Seed (oil/wax) & Biolubricants & {$[44-46]$} \\
\hline Seed (oil) & Biodiesel & {$[47,48]$} \\
\hline Simmondsin and its derivatives & Antifungal & {$[34]$} \\
\hline Meal (left over after oil-extraction) & Livestock feed & {$[17]$} \\
\hline Seed (oil) & Bioenergy & {$[13]$} \\
\hline Ethanolic extract & Inhibit oxidative stress induced by fumonisins (mycotoxins) & {$[30]$} \\
\hline Seed (oil) & Anti-inflammatory (e.g.: treatment for throat inflammation, wound treatment) & {$[14]$} \\
\hline Seed (oil) & Relief for headaches & [14] \\
\hline Oil and seed extracts & Antimicrobial and antifungal & {$[32,33,35]$} \\
\hline Seed (oil) & Synthetic polymer & {$[12]$} \\
\hline Meal & Fish meal of Nilotica fish (Oreochromis niloticus) & {$[18]$} \\
\hline Seed (oil) & Selective froth flotation for phosphate ores extraction & {$[39]$} \\
\hline Leaves (flavonoid compounds) & Antioxidant and lipoxygenase inhibitor & {$[84]$} \\
\hline Leaves and seed coats & Antibacterial and anticancer & {$[20]$} \\
\hline Seed (oil) & Lipoxygenase inhibitor & {$[28]$} \\
\hline Simmondsin and its derivatives & Antioxidant & {$[20,31]$} \\
\hline Seed (oil) & Pharmaceuticals & {$[11]$} \\
\hline Seed (oil) & Skincare treatment & {$[37]$} \\
\hline Meal & Anti-rodent & {$[19]$} \\
\hline Seed (oil) & Antifungal/insecticidal properties & {$[16]$} \\
\hline Crude extracts & Cyclooxygenase inhibitor (anticarcinogenic) & {$[16]$} \\
\hline
\end{tabular}


$50{ }^{\circ} \mathrm{C}$ are believed to suppress growth, although they are not lethal [51]. Jojoba is a dioecious species-i.e., having separate male and female plants (Fig. 1d). Only the females, however, provide the valuable seeds [52]. When raised through seeds, about $50 \%$ or more of the seedlings are males [53]. The sex can be recognized only when the plants start bearing after 3-4 years of planting, while for an efficient commercial yield, no more than a $10 \%$ male population is required [54]. The success of jojoba growers, and indeed of the entire jojoba industry, depends upon the selection of high-yielding genotypes and their multiplication through vegetative means. Propagating jojoba by direct seeding has genetic heterogeneity, which has raised doubts about the economic feasibility of cultivating jojoba [55]. Vegetative propagation can be achieved by rooting or grafting semi-hardwood cuttings. However, the highest number of propagules is restricted by the size of the plant and time of year [56]. Micropropagation of the best-selected individuals exploits potential genetics of plant cells and offers a capable means of profitable mass production of disease-free elite clones. In vitro-derived cultivated jojoba plants grow more dynamically than both seedlings and rooted cuttings, and the plant size is significantly bigger after a few months of growth. Size and age of cuttings and time of taking the cuttings also affect the rooting percentage in jojoba [10]. Rooting of jojoba stem cuttings is considered the most common and easiest asexual propagation method in jojoba [10]. Soil media used for planting the cuttings or for subsequent transplanting may affect the rooting of cuttings as well as their growth and survival. Khattab et al. [57] investigated the effect of different factors, such as the date of collecting cuttings, plant wounding, and dipping the plant cuttings into chemical treatments, on the propagation success percentage. As a result, it was concluded that using wounded cuttings in summer (end of July) recorded a significantly higher success rate than that of unwounded cuttings. [57]

Jojoba seedlings develop deeply penetrating tap roots, allowing them to access water and nutrients stored deep in the soil, while saplings tend to produce a more fibrous root system unable to sustain them under stressful conditions. Fertilization during rooting was not found to increase the rooting percentage. However, it was found to increase tissue nutrient levels and growth of rooted cuttings [58]. Application of liquid fertilizer containing zinc, potassium, and/or ascorbic acid positively affected the physiological functions and growth criteria of the tested plants compared with a control jojoba plant [59]. Results indicated that jojoba plants seem to have better growth after being sprayed in mid-March with micronutrient fertilizers in both green- and shade-house conditions [60]. A study conducted by Bala et al. [1] on the effect of various soil media on seed germination of jojoba under in vivo conditions showed the highest percentage of seed germination in the desert soil mixed with farmyard manure at a ratio of $2: 1$, and it recommends prior germination of seeds under nursery conditions to raise potentially healthy plantlets for the successful establishment in the field. Cultivation of the jojoba plant has been threatened by bacterial and fungal diseases. One of the first fungal diseases reported was in Australia [61], and Pleospora herbarum was reported to cause jojoba leaf spots. In Arizona, it was reported that Phytophthora parasitica caused jojoba leaf blight [62]. Ganoderma lucudium infection and colonization has been reported in India [63]. Collar rot caused by Fusarium oxysporum was also reported in Australian jojoba plantations [64], while the first bacterial disease caused by the soil bacterium Burkholderia andropogonis was also found in Australia [65]. Collar and root rot of jojoba caused by Phytophthora nicotianae were previously reported in Argentina [66]. Ash et al. [67] reported black scab of jojoba in Australia caused by the fungus Elsinoë australis. Omar and his co-authors recently reported a new bacterial infection (Candidatus Phytoplasma) of jojoba in Saudi Arabia [68]. In spite of these disease reports, there is no study describing the economic impact of these pathogens on jojoba plantations and how these pathogens affect the oil productivity.

\section{Genetic diversity and molecular biology approaches}

Being a dioecious species, a higher level of cross pollination has resulted in a wide genetic variability represented by hundreds of cultivars. Only a small percentage of the plant population originating from seeds produce a high quantity and desirable quality of oil [55]. Hence, the selection of high-yielding varieties and their clonal propagation was started with the aim of producing seeds of desired qualities. The present cultivations of this plant are mainly via vegetative propagation from a limited number of selected landraces which are consequently used in the cultivation of many more varieties. The largescale cultivation of such genetically constant cultivars has resulted in a progressively less genetic bias for the crops, leading to genetic vulnerability [54]. For more maintainable and valuable production of jojoba, understanding the extent and association of genetic variations and their relationships is essential. Molecular markers work as a significant tool to check that genetic homogeneity in micropropagated plants is as expected. However, such reports are very limited in jojoba [22]. A summary of the molecular biology studies involved is provided in Table 2 . As early as 1995, a random amplified polymorphic DNA (RAPD) technique for the differentiation between two 
Table 2 Summary of molecular biology-based research performed on jojoba (Simmondsia chinensis)

\begin{tabular}{|c|c|c|}
\hline Molecular techniques & Targets & References \\
\hline RAPD & Genetic variability & [69] \\
\hline RAPD & Gender differentiation & [53] \\
\hline ISSR & Gender marker-assisted selections & [70] \\
\hline RAPD, ISSR & Genetic relationship among and between gender & [71] \\
\hline RAPD, ISSR & Assessment of ISSR and RAPD marker assays for genetic diversity analysis & [21] \\
\hline Touch-down PCR assay & Gender diagnostic & [73] \\
\hline RAPD, ISSR & Clone maintenance & [72] \\
\hline AFLP & Gender-linked AFLP markers & [74] \\
\hline CAPS & Early gender differentiation & [52] \\
\hline RAPD & In vitro and in vivo gender differentiation & [75] \\
\hline ISSR & Genetic variation and chemical traits of selected plants & {$[76,77]$} \\
\hline ISSR, SCAR & Early gender differentiation & [6] \\
\hline ISSR & Male-specific sequence tagged sites marker & [78] \\
\hline ISSR & Male-specific sequence tagged sites marker & [79] \\
\hline SCOT, CBDP & Gender genetic diversity & [54] \\
\hline RAPD, GC-MS technique & Validation of different jojoba accessions for commercial applications & [80] \\
\hline Gel based proteomics coupled with real time-PCR & Protein-based biomarker & {$[82]$} \\
\hline
\end{tabular}

jojoba clones at the genomic level was applied [69]. In that study, out of 30 primers tested, a simple reproducible design with three different fragments for clone ' $D$ ' and two distinct fragments for clone ' $E$ ' was obtained with printer OPB08. For the gender identification of dioecious jojoba, RAPD [53] and ISSR [70] marker-assisted selections were employed. Comparative assessments of ISSR and RAPD marker assays for detecting genetic diversity in jojoba were also done [71]. Bhardwaj et al. [21] analysed a collection of male and female plants of 10 jojoba genotypes with 50 RAPD and 55 ISSR markers to compare the efficiency and utility of these techniques for detecting genetic polymorphism. RAPD and ISSR analysis yielded 442 and 566 scorable amplified products, respectively, of which 60.7 and $69.3 \%$ were polymorphic. ISSRs revealed efficiency over RAPDs due to high EMR (effective multiplex ratio), DI (diversity index, mean PIC per primer) and MI (marker index) values [21].

Using ISSR and RAPD markers, it was shown that axillary bud multiplication is a safe method for production of true-to-type plants in jojoba [72]. A reliable gender diagnostic PCR assay [73] and CAPS assay [52] for jojoba were also reported. AFLP markers were also successfully employed in gender determination of jojoba cultivars [74]. Al-Obaidi et al. [75] developed a set of RAPD-PCRbased biomarkers for both in vitro and in vivo jojoba cultivars. Al-Soqeer et al. [76] observed highly significant differences among six jojoba genotypes in oil, protein, total carbohydrate and simmondsin contents. They compared the molecular data obtained from ISSR markers with the chemical traits obtained from the same genotypes. The tree diagram generated using collective ISSR data separated the jojoba genotypes into two main groups. Genotypes found in the same sub-cluster using ISSR primers also had almost similar values for most chemical traits. Moreover, Al-Soqeer and his co-authors [77] found a large genetic variability among seven jojoba genotypes in growth, vegetative, reproductive and seedyield characteristics. Early diagnosis of sex in Jojoba using a male-specific inter-simple sequence repeat marker was developed [6]. The group managed to amplify a fragment of approximately $1000 \mathrm{bp}$ in male plants. That fragment was completely absent in female plants. Another unique male-specific sequence tagged sites (STS) marker was generated from diverse genotypes of jojoba [78], and the same group also validated a male sex-specific UBC$8071_{200}$ ISSR marker and its conversion into sequence tagged sites [79]. Two types of gene targeted markersstart codon targeted (SCoT) polymorphism and CAAT box-derived polymorphism (CBDP) - were developed to detect genetic variations among different Simmondsia chinensis genotypes [54].

In a recent study, both molecular analysis and biochemical fingerprinting cumulatively revealed a significant level of variability among 18 accessions of the jojoba plant collected from Rajasthan, India [80]. Ten major fatty acids were found in all the accessions, and of these, oleic acid (OA) was in high concentration. Further OA content of individual accessions was correlated with RAPD analysis data. Genomic DNA sequencing is considered important information which can be used for assessment and improvement of plants [81]. Recently, it 
has been revealed that proteins involved in metabolism, energy biotic and abiotic stress exhibit differences with high expression level in male compared to the female plants [82]. The potential benefit of molecular assessment in the jojoba plant could enable screening of its varieties of high oil quality and quantity, and examine the factors in which they are hereditarily identical. Jojoba research is still in its infancy with respect to genetic improvement. Future research should focus on jojoba genome sequencing, which is considered a very important step. The jojoba genome will enable future research on the evolution of the study of the oil biosynthesis process and composition, potential genetic improvement and gender selection for this homomorphic plant. Research and development should focus on the oil biosynthesis pathways and be selective for biological markers for high oil yield and earlier-flowering plants. The molecular-based research on the plant growth, seed generation and oil development process of jojoba will be an essential step towards suitable and profitable jojoba cultivation. This information will help the future study of gene expression involved in the oil biosynthesis process. Bearing in mind the plant's massive potential, a large amount of high-quality planting material is essential for its forthcoming applications. Many research groups have been working on the improvement of jojoba through traditional selection or breeding programs, but the biomass volume is considered low in comparison to other oil crops [83]. Importantly, biomass, oil yield, and early detection of plant gender can be improved by applying molecular biology techniques that will accelerate this process. Development platforms of jojoba cultivation by modern methods of agro-biotechnology are of concern worldwide, not only for oil production but for combatting desertification. Therefore, there is an urgent need to create high-quality genotypes for successful application of jojoba cultivation. High throughput 'omics' research such as transcriptomics and metabolomics research platforms will also be favourable approaches to study oil production stages and for more efficient early gender-based differentiation research.

\section{Abbreviations \\ DPPH: 1,1-diphenyl-2-picryl-hydrazyl; COX-2: cyclooxygenase-2; ISSR: inter- simple sequence repeat; AFLP: amplified fragment length polymorphism; CAPS: cleaved amplified polymorphic sequences; PCR: polymerase chain reaction; SCAR: sequence characterized amplified region; SCoT: start codon targeted; MRSA: methicillin-resistant Staphylococcus aureus.}

\section{Authors' contributions}

JRA wrote the abstract, introduction and contributed in the agronomy aspect, MFH wrote medical aspect, NSA wrote the commercial importance of jojoba, SA and AAA wrote genetic diversity and molecular biology approaches, MFA wrote agronomy aspect. All authors read and approved the final manuscript.

\begin{abstract}
Author details
${ }^{1}$ Agro-Biotechnology Institute Malaysia (ABI), c/o MARDI Headquarters, 43400 Serdang, Selangor, Malaysia. ${ }^{2}$ Department of Biology, Faculty of Science and Art, Taibah University, Al-Ula 43522, Saudi Arabia. ${ }^{3}$ King Abdulaziz City for Science and Technology (KACST), P.O. Box 6086, Riyadh, Saudi Arabia. ${ }^{4}$ Department of Plant Production and Protection, College of Agriculture and Veterinary Medicine, Qassim University, Buraydah 51452, Saudi Arabia.

${ }^{5}$ Soil Fertility and Microbiology Department, Desert Research Center, Cairo, Egypt.
\end{abstract}

\begin{abstract}
Acknowledgements
The authors would like to thank the Service and Training unit ABI (STU-ABI) and the national institutes of biotechnology Malaysia (NIBM) for their help and support.
\end{abstract}

\section{Competing interests}

The authors declare that they have no competing interests.

Consent for publication

Not applicable.

Ethics approval and consent to participate

Not applicable.

\section{Funding}

No funds were involved.

\section{Publisher's Note}

Springer Nature remains neutral with regard to jurisdictional claims in published maps and institutional affiliations.

Received: 23 February 2017 Accepted: 16 August 2017

Published online: 24 August 2017

\section{References}

1. Bala R, Beniwal VS, Laura JS. An efficient and reproducible indirect shoot regeneration from female leaf explants of Simmondsia chinensis, a liquidwax producing shrub. Physiol Mol Biol Plants. 2015;21 (2):293-9.

2. Larraburu EE, Bususcovich AC, Llorente BE. Azospirillum brasilense improves in vitro and ex vitro rooting-acclimatization of jojoba. Sci Hortic. 2016;209:139-47.

3. Abdel-Mageed WM, Bayoumi SALH, Salama AAR, Salem-Bekhit MM Abd-Alrahman SH, Sayed HM. Antioxidant lipoxygenase inhibitors from the leaf extracts of Simmondsia chinensis. Asian Pac J Trop Med. 2014;7:S521-6.

4. Miklaszewska M, Banaś A. Biochemical characterization and substrate specificity of jojoba fatty acyl-CoA reductase and jojoba wax synthase. Plant Sci. 2016;249:84-92.

5. Lei Q, LiT. Functional monoesters of jojoba oil can be produced by enzymatic interesterification: reaction analysis and structural characterization. Eur J Lipid Sci Technol. 2015;117(5):630-6.

6. Jangra S, Kharb P, Mitra C, Uppal S. Early diagnosis of sex in jojoba, Simmondsia chinensis (link) schneider by sequence characterized amplified region marker. Proc Natl Acad Sci India Sect B Biol Sci. 2014;84(2):251-5.

7. Fouillen L, Colsch B, Lessire R. Chapter seven - the lipid world concept of plant lipidomics. In: Dominique R, editor. Advances in botanical research, vol. 67. Cambridge: Academic Press; 2013. p. 331-76.

8. Fouts C, Pavlovic A, Rohde S, Quinn J. Derivatives of esters. In Google Patents; 2015

9. Sandha G, Swami V. Jojoba oil as an organic, shelf stable standard oilphase base for cosmetic industry. Rasayan J Chem. 2009;2(2):300-6.

10. Bashir MA, Mushtaq A, Anjum MA. Effect of various potting media on growth of rooted jojoba (Simmondsia chinensis) cuttings. Int J Agric Biol. 2007:9:147-51.

11. Sánchez M, Marchetti JM, Boulifi NE, Martínez M, Aracil J. Jojoba oil biorefinery using a green catalyst. Part I: simulation of the process. Biofuels Bioprod Biorefin. 2015;9(2):129-38. 
12. Ifuku O. Chapter 20-botanical ingredients. In: Cosmetic science and technology. Amsterdam: Elsevier; 2017. p. 305-320.

13. Le Dréau Y, Dupuy N, Gaydou V, Joachim J, Kister J. Study of jojoba oil aging by FTIR. Anal Chim Acta. 2009;642(1-2):163-70.

14. Ranzato E, Martinotti S, Burlando B. Wound healing properties of jojoba liquid wax: an in vitro study. J Ethnopharmacol. 2011;134(2):443-9.

15. Habashy RR, Abdel-Naim AB, Khalifa AE, Al-Azizi MM. Anti-inflammatory effects of jojoba liquid wax in experimental models. Pharmacol Res. 2005;51(2):95-105.

16. Abdel-Mageed WM, Bayoumi SAL, Al-wahaibi LH, Li L, Sayed HM, Abdelkader MSA, El-Gamal AA, Liu M, Zhang J, Zhang L, Liu X. Noncyanogenic cyanoglucoside cyclooxygenase inhibitors from Simmondsia chinensis. Org Lett. 2016;18(8):1728-31.

17. Bouali A, Bellirou A, Boukhatem N, Hamal A, Bouammali B. Enzymatic detoxification of jojoba meal and effect of the resulting meal on food intake in rats. Nat Prod Res. 2008;22(7):638-47.

18. Labib EMH, Ha MAZ. Nutritional studies on partial and total replacement of fishmeal by jojoba meal (Simmondsia chinensis) in Nile tilapia (Oreochromis niloticus) fingerlings diets. APCBEE Procedia. 2012;4:196-203.

19. Chaudhary V, Tripathi RS. Feeding deterrence effects of defatted jojoba (Simmondisa chinensis) meal against Indian gerbil, Tatera indica (Hardwicke). Proc Natl Acad Sci India Sect B Biol Sci. 2015;87(3):1-8.

20. Al-Qizwini H, Ekbal AK, Mhaidat NM, Maraqa A. Antioxidant and antimicrobial activities of jordanian Simmondsia chinensis (link) ck schneid. Eur Sci J. 2014;10:229-41.

21. Bhardwaj M, Uppal S, Jain S, Kharb P, Dhillon R, Jain RK. Comparative assessment of ISSR and RAPD marker assays for genetic diversity analysis in jojoba [Simmondsia chinensis (Link) Schneider]. J Plant Biochem Biotechnol. 2010;19(2):255-8.

22. Reddy MP. Desert Plant Biotechnology: Jojoba, Date Palm, and Acacia Species. In: Bahadur B, Venkat Rajam M, Sahijram L, Krishnamurthy KV, editors. Plant biology and biotechnology: volume II: plant genomics and biotechnology. New Delhi: Springer India; 2015. p. 725-41.

23. Hill K, Hofer R. Natural fats and oils. In: Sustainable solutions for modern economies. The Royal Society of Chemistry; 2009. p. 167-237.

24. Kar A, Rajaguru SN, Singhvi AK, Juyal N. Chronostratigraphic evidence for episodes of desertification since the Last Glacial Epoch in the southern margin of Thar desert, India. In: Desertification in the Third Millennium. Taylor \& Francis; 2003. p. 123-128.

25. McKeon TA. Emerging industrial oil crops. In: Industrial oil crops. AOCS Press; 2016. p. 275-341.

26. Gillespie KM, Chae JM, Ainsworth EA. Rapid measurement of total antioxidant capacity in plants. Nat Protoc. 2007;2(4):867-70.

27. Sharma SK, Singh AP. Pharmacognostical evaluation of roots of Simmondsia chinensis Schneider. Int J Pharm Sci Drug Res. 2011;3:323-6.

28. Abdul-Hafeez EY, Karamova NS, llinskaya ON. Antioxidant activity and total phenolic compound content of certain medicinal plants. Int J Biosci. 2014:5(1):213-22.

29. Bryła M, Roszko M, Szymczyk K, Jędrzejczak R, Obiedziński MW, Sękul J. Fumonisins in plant-origin food and fodder-a review. Food Addit Contam Part A. 2013;30(9):1626-40.

30. Abdel-Wahhab M, Sharaf H, Abou-Salem F. Jojoba extract counteracts oxidative stress in rats fed fumonisin-contaminated diet. Toxicol Lett. 2010;196:S328.

31. Manoharan S, Vishnupriya V Gayathri R. Phytochemical analysis and in vitro antioxidant activity of jojoba oil. J Pharm Sci Res. 2016;8(6):512-6.

32. Abu-Salem F, Ibrahim HM. Antimicrobial activity and phytochemicals screening of jojoba (Simmondsia chinensis) root extracts and latex. Int J Biol Biomol Agric Food Biotechnol Eng. 2014;8(5):516-22.

33. Elnimiri K, Nimir H. Biological and chemical assessment of the Sudanese jojoba (Simmondsia chinensis) oil. Int J Nat Prod Pharm Sci. 2011;2(1):28-39.

34. Abbassy MA, Abdelgaleil SAM, Belal ASH, Rasoul MAAA. Insecticidal, antifeedant and antifungal activities of two glucosides isolated from the seeds of Simmondsia chinensis. Ind Crops Prod. 2007;26(3):345-50.

35. Menghani E, Khan S, Soni M. Search for antimicrobial potentials from Simmondsia chinensis. Int J Pharm Sci Res. 2012;3(7):2093.

36. Fu S-L, Wu Y-L, Zhang Y-P, Qiao M-M, Chen Y. Anti-cancer effects of COX-2 inhibitors and their correlation with angiogenesis and invasion in gastric cancer. World J Gastroenterol WJG. 2004;10(13):1971-4.

37. Henderson A. Oil blend for skin treatment. In Google Patents; 2015.
38. Santos EP, Dutra AJB, Oliveira JF. The effect of jojoba oil on the surface properties of calcite and apatite aiming at their selective flotation. Int J Miner Process. 2015;143:34-8.

39. Lawal SA, Choudhury IA, Nukman Y. A critical assessment of lubrication techniques in machining processes: a case for minimum quantity lubrication using vegetable oil-based lubricant. J Clean Prod. 2013;41:210-21.

40. Suarez PA, Moser BR, Sharma BK, Erhan SZ. Comparing the lubricity of biofuels obtained from pyrolysis and alcoholysis of soybean oil and their blends with petroleum diesel. Fuel. 2009;88(6):1143-7.

41. Yilmaz N. Temperature-dependent viscosity correlations of vegetable oils and biofuel-diesel mixtures. Biomass Bioenergy. 2011;35(7):2936-8.

42. Quinchia L, Delgado M, Valencia C, Franco J, Gallegos C. Viscosity modification of different vegetable oils with EVA copolymer for lubricant applications. Ind Crops Prod. 2010;32(3):607-12.

43. Mejia J, Salgado N, Orrego C. Effect of blends of diesel and palm-castor biodiesels on viscosity, cloud point and flash point. Ind Crops Prod. 2013:43:791-7.

44. Alotaibi J, Yousif B. Biolubricants and the potential of waste cooking oil. In: Ecotribology. Springer; 2016. p. 125-143.

45. Sivasankaran G, Bisht R, Jain V, Gupta M, Sethuramiah A, Bhatia V. Jojoba-oil-based two-stroke gasoline engine lubricant. Tribol Int. 1988;21(6):327-33.

46. Bhatia V, Chaudhry A, Sivasankaran G, Bisht R, Kashyap M. Modification of jojoba oil for lubricant formulations. J Am Oil Chem Soc. 1990;67(1):1-7.

47. Canoira L, Alcántara R, Jesús García-Martínez M, Carrasco J. Biodiesel from jojoba oil-wax: transesterification with methanol and properties as a fuel. Biomass Bioenergy. 2006;30(1):76-81.

48. Shah M, Ali S, Tariq M, Khalid N, Ahmad F, Khan MA. Catalytic conversion of jojoba oil into biodiesel by organotin catalysts, spectroscopic and chromatographic characterization. Fuel. 2014;118:392-7.

49. Brooks W. Jojoba: North American desert shrub; its ecology, possible commercialization, and potential as an introduction into other arid regions (Simmondsia chinensis). J Arid Environ. 1978; 1(3).

50. Gentry HS. The natural history of jojoba (Simmondsia chinensis) and its cultural aspects. Econ Bot. 1958;12:261-95.

51. Ash GJ, Albiston A, Cother EJ. Aspects of jojoba agronomy and management. In: Advances in agronomy, vol. 85. Academic Press; 2005. p. 409-437.

52. Ince AG, Karaca M. Early determination of sex in jojoba plant by CAPS assay. J Agric Sci. 2011;149(3):327-36.

53. Agrawal V, Sharma K, Gupta S, Kumar R, Prasad M. Identification of sex in Simmondsia chinensis (Jojoba) using RAPD markers. Plant Biotechnol Rep. 2007;1 (4):207-10

54. Heikrujam M, Kumar J, Agrawal V. Genetic diversity analysis among male and female jojoba genotypes employing gene targeted molecular markers, start codon targeted (SCOT) polymorphism and CAAT box-derived polymorphism (CBDP) markers. Meta Gene. 2015;5:90-7.

55. Kumar S, Mangal M, Dhawan AK, Singh N. Biotechnological advances in jojoba [Simmondsia chinensis (Link) Schneider]: recent developments and prospects for further research. Plant Biotechnol Rep. 2012;6(2):97-106.

56. Llorente BE, Apóstolo NM. In Vitro Propagation of Jojoba. In: Lambardi M, Ozudogru EA, Jain SM, editors. Protocols for micropropagation of selected economically-important horticultural plants. Totowa: Humana Press; 2013. p. 19-31.

57. Khattab MM, Hegazi AA, Elsayed ME, Hassan AZ. Jojoba propagation by leafy semi hardwood stem cuttings. World J Agric Sci. 2014;10(1):34-8.

58. Feldman W. Photosynthesis, respiration and growth of jojoba throughout the year. In: Proceedings of the Seventh International Conference on jojoba and its uses; 1988. p. 1-19.

59. Hussein M, Alva A. Effects of zinc and ascorbic acid application on the growth and photosynthetic pigments of millet plants grown under different salinity. Agric Sci. 2014:5(13):1253.

60. Eed AM, Burgoyne AH. Propagation of Simmondsia chinensis (Link) Schneider by stem cuttings. Biol Chem Res. 2015;2015:268-75.

61. Woodcock T. Pleospora leaf spot of jojoba. Australas Plant Pathol. 1983:12:14-5.

62. Alcorn S. Phytophthora leaf blight of jojoba (Simmondsia chinensis) in Arizona. Dis Note. 1989:76:444.

63. Lodha S, Dwivedi NK, Bhandari DC, Bohra MD. Infection and colonization of jojoba by Ganoderma lucidum. Phytoparasitica. 1994;22(3):229-31. 
64. Albiston A, Ash GJ, Cother EJ, Bentley S, Pattemore J. First record of collar rot caused by Fusarium oxysporum in Australian jojoba plantations. Australas Plant Pathol. 2003;32(2):319-20.

65. Cother EJ, Noble D, Peters BJ, Albiston A, Ash GJ. A new bacterial disease of jojoba (Simmondsia chinensis) caused by Burkholderia andropogonis. Plant Pathol. 2004;53(2):129-35.

66. Lucero G, Vettraino AM, Pizzuolo P, Vannini A. First report of Phytophthora nicotianae on jojoba in Argentina. Plant Pathol. 2006;55(2):295.

67. Ash G, Stodart B, Hyun J-W. Black scab of jojoba (Simmondsia chinensis) in Australia caused by a putative new pathotype of Elsinoë australis. Plant Dis. 2012;96(5):629-34.

68. Omar AF, Pérez-López E, Al-Jamhan KM, Dumonceaux TJ. First report of a new jojoba (Simmondsia chinensis) Witches'-broom disease in Saudi Arabia and its Association With Infection by a 'Candidatus Phytoplasma australasiae'-related phytoplasma strain. Plant Dis. 2017;101(8):1540.

69. Amarger V, Mercier L. Molecular analysis of RAPD DNA based markers: their potential use for the detection of genetic variability in jojoba ( $\mathrm{Sim}$ mondsia chinensis L. Schneider). Biochimie. 1995;77(12):931-6.

70. Sharma K, Agrawal V, Gupta S, Kumar R, Prasad M. ISSR marker-assisted selection of male and female plants in a promising dioecious crop: jojoba (Simmondsia chinensis). Plant Biotechnol Rep. 2008;2(4):239-43.

71. Sharma R, Chowdhury VK, Jain S, Jain R. A comparative study of genetic relationships among and within male and female genotypes of dioecious jojoba (Simmondsia chinensis L Schneider) using RAPD and ISSR markers. Asian J Hortic. 2009;4:184-93.

72. Kumar S, Mangal M, Dhawan AK, Singh N. Assessment of genetic fidelity of micropropagated plants of Simmondsia chinensis (Link) Schneider using RAPD and ISSR markers. Acta Physiol Plant. 2011;33(6):2541-5.

73. Ince AG, Karaca M, Onus AN. A reliable gender diagnostic PCR assay for jojoba (Simmondsia chinensis (Link) Schneider). Genet Resour Crop Evol. 2010;57(5):773-9.

74. Agarwal M, Shrivastava N, Padh H. Development of sex-linked AFLP markers in Simmondsia chinensis. Plant Breed. 2011;130(1):114-6.

75. Al-Obaidi JR, Suliman BK, Al-Ani NK. Molecular-based marker for sex differentiation of jojoba in vivo and in vitro Iraqi cultivars using RAPD-PCR technique. Sci Res Essays. 2012;7(4):522-7.
76. Al-Soqeer A, Motawei MI, Al-Dakhil M, El-Mergawi R, Al-Khalifah N Genetic variation and chemical traits of selected new jojoba (Simmondsia chinensis (Link) Schneider) genotypes. J Am Oil Chem Soc. 2012;89(8):1455-61.

77. Al-Soqeer A. Evaluation of seven jojoba (Simmondsia chinensis) clones under Qassim Region conditions in Saudi Arabia. Int J Agric Sci Res. 2014;3(10):203-12.

78. Heikrujam M, Sharma K, Kumar J, Agrawal V. Generation and validation of unique male sex-specific sequence tagged sites (STS) marker from diverse genotypes of dioecious jojoba-Simmondsia chinensis (Link) Schneider. Euphytica. 2014;199(3):363-72.

79. Heikrujam M, Sharma K, Kumar J, Agrawal V. Validation of male sex-specific UBC-8071200ISSR marker and its conversion into sequence tagged sites marker in jojoba: a high precision oil yielding dioecious shrub. Plant Breed. 2014;133(5):666-71.

80. Arya D, Agarwal S, Khan S. Authentication of different accessions of Simmondsia chinensis (Link) Schneider (jojoba) by DNA fingerprinting and chromatography of its oil. Ind Crops Prod. 2016;94:376-84.

81. Mukherjee P, Varshney A, Johnson TS, Jha TB. Jatropha curcas: a review on biotechnological status and challenges. Plant Biotechnol Rep. 2011;5(3):197-215.

82. Al-Obaidi JR, Rahmad N, Hanafi NM, Halabi MF, Al-Sogeer AA. Comparative proteomic analysis of male and female plants in jojoba (Simmondsia chinensis) leaves revealed changes in proteins involved in photosynthesis, metabolism, energy, and biotic and abiotic stresses. Acta Physiol Plant. 2017:39(8):179.

83. Reddy MP, Chikara J. Biotechnology advances in jojoba (Simmondsia chinensis). In: Ramawat KG, editor. Desert plants: biology and biotechnology. Berlin: Springer; 2010. p. 407-21.

84. Abdel-Mageed WM, Bayoumi SALH, Salama AAR, Salem-Bekhit MM, AbdAlrahman SH, Sayed HM. Antioxidant lipoxygenase inhibitors from the leaf extracts of Simmondsia chinensis. Asian Pac J Trop Dis. 2014;7:S521-6.

\section{Submit your next manuscript to BioMed Central and we will help you at every step:}

- We accept pre-submission inquiries

- Our selector tool helps you to find the most relevant journal

- We provide round the clock customer support

- Convenient online submission

- Thorough peer review

- Inclusion in PubMed and all major indexing services

- Maximum visibility for your research

Submit your manuscript at www.biomedcentral.com/submit
() Biomed Central 